\title{
Characterization of giant marker and ring chromosomes in a pleomorphic leiomyosarcoma of soft tissue by spectral karyotyping
}

\author{
JUN NISHIO $^{1}$, MIKIKO AOKI ${ }^{2}$, KAZUKI NABESHIMA $^{2}$, HIROSHI IWASAKI $^{2}$ and MASATOSHI NAITO ${ }^{1}$ \\ Departments of ${ }^{1}$ Orthopaedic Surgery and ${ }^{2}$ Pathology, Faculty of Medicine, Fukuoka University, Fukuoka, Japan
}

Received January 31, 2012; Accepted April 13, 2012

DOI: $10.3892 /$ or.2012.1835

\begin{abstract}
Pleomorphic leiomyosarcoma of soft tissue is relatively rare and its cytogenetic and molecular genetic data are scarce. We present a case of pleomorphic leiomyosarcoma arising in the left thigh of a 60-year-old man. Fluorine-18deoxyglucose positron emission tomography imaging showed a homogenously high uptake within the mass in the proximal left thigh (maximum standardized uptake value, 20.9). Following a core needle biopsy, wide resection of the tumor was performed. Histologically, the tumor was composed of a mixture of spindle cells, polygonal cells and bizarre giant cells forming interlacing bundles and a storiform pattern. Immunohistochemically, the tumor cells were positive for vimentin, smooth muscle actin and desmin. The MIB-1 labeling index was $19.7 \%$ in the highest spot. Cytogenetic analysis exhibited a complex karyotype with several numerical and structural alterations, including giant marker and ring chromosomes. Spectral karyotyping demonstrated that giant marker and ring chromosomes were composed of material from the X chromosome. Metaphasebased comparative genomic hybridization analysis showed high-level amplifications of 1q21-q25 and 12q13-q21 and gains of 1p31-p32, 10p11-p13, 17p11 and 19p13. The patient received postoperative adjuvant radiotherapy and doxorubicin-based chemotherapy. No local recurrence or distant metastasis was detected during a follow-up period of 19 months. The clinicopathological, cytogenetic and molecular genetic features of pleomorphic soft tissue leiomyosarcoma are discussed.
\end{abstract}

\section{Introduction}

Pleomorphic leiomyosarcoma is a rare but distinct variant of leiomyosarcoma, accounting for only $8.6 \%$ of all leiomyosarcomas (1). It occurs predominantly in the retroperitoneum and extremities of middle-aged to elderly adults. In general,

Correspondence to: Dr Jun Nishio, Department of Orthopaedic Surgery, Faculty of Medicine, Fukuoka University, 7-45-1 Nanakuma, Jonan-ku, Fukuoka 814-0180, Japan

E-mail: jnishio@cis.fukuoka-u.ac.jp

Key words: leiomyosarcoma, cytogenetics, marker chromosome, spectral karyotyping pleomorphic leiomyosarcoma has an aggressive behavior with a 48-89\% metastatic rate and an overall tumor-associated mortality of $50-65 \%(1,2)$. Retroperitoneal leiomyosarcomas tend to correlate with a higher frequency of local recurrence and distant metastasis, probably due to the difficulty in achieving wide or even clear margins.

Histologically, pleomorphic leiomyosarcoma is defined as a tumor composed of typical leiomyosarcoma with pleomorphic areas occupying more than two-thirds of the lesion (1). The typical component consists of spindle-shaped cells with brightly eosinophilic cytoplasm and cigar-shaped nuclei arranged in a fascicular pattern. In contrast, the pleomorphic component is composed of polygonal cells, spindle-shaped cells, and/ or epithelioid cells, simulating the morphology of so-called malignant fibrous histiocytoma (MFH). Multinucleated bizarre cells and rhabdoid cells may be found in the pleomorphic component $(1,2)$. Immunohistochemically, the tumor cells are positive for at least one of the smooth muscle markers (smooth muscle actin, desmin, muscle-specific actin, calponin, and caldesmon) in both the typical and pleomorphic components.

Pleomorphic soft tissue leiomyosarcomas are generally associated with highly complex karyotypes lacking specific structural or numerical aberrations (3-5). Metaphase and array-based comparative genomic hybridization (CGH) analyses have demonstrated gains of 1q, 5p, 6q, 8q, 17p, and Xp and losses of 2p, 10q, 11q, 13q, and 16q. Amplifications of 1q21, 5p14-pter, 12q13-q15, 17p11-p12, 19p13, and 20q13 have also been observed (5-13).

In this study, we report a case of pleomorphic leiomyosarcoma with giant marker and ring chromosomes occurring in the deep soft tissue of the thigh. We also review the cytogenetic and molecular cytogenetic features of pleomorphic soft tissue leiomyosarcoma as well as its clinicopathological characteristics.

\section{Materials and methods}

Case presentation. A 60-year-old man was referred to our hospital with a history of a non-painful left thigh mass first noticed one month previously. Physical examination revealed an $8 \times 7 \mathrm{~cm}$, firm, non-tender mass in the medial aspect of the proximal left thigh. Magnetic resonance imaging revealed an ill-defined intramuscular mass in the left adductor magnus. The mass was low to intermediate signal intensity on T1-weighted sequences (Fig. 1A) and heterogeneously high signal intensity 

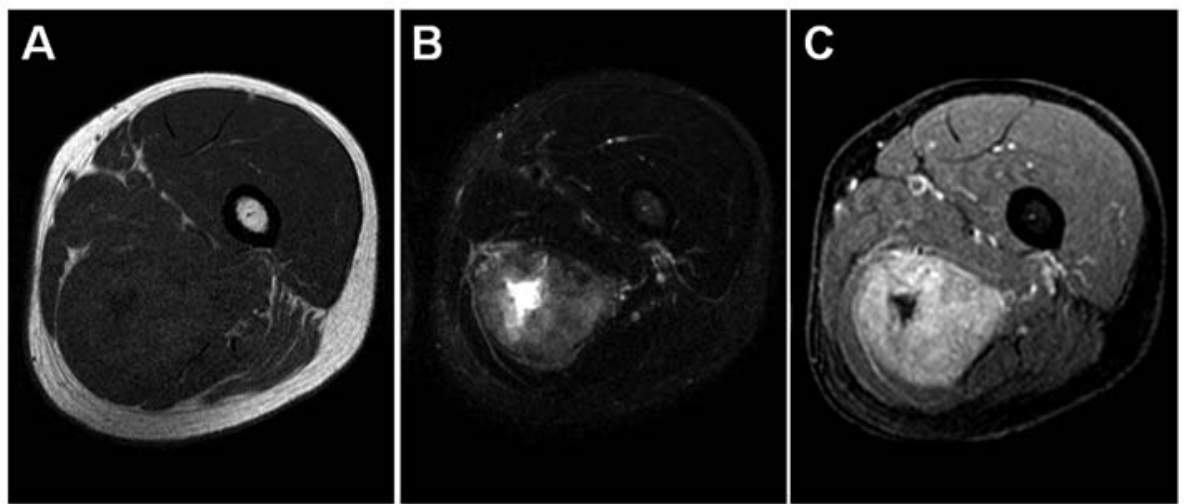

Figure 1. Axial magnetic resonance images of pleomorphic leiomyosarcoma involving the left thigh. (A) T1-weighted sequence shows that the mass has low to intermediate signal intensity. (B) T2-weighted spectral presaturation with inversion recovery sequence shows that the mass has heterogeneously high signal intensity. (C) T1-weighted contrast-enhanced fat-suppressed sequence shows heterogenous enhancement throughout the mass.
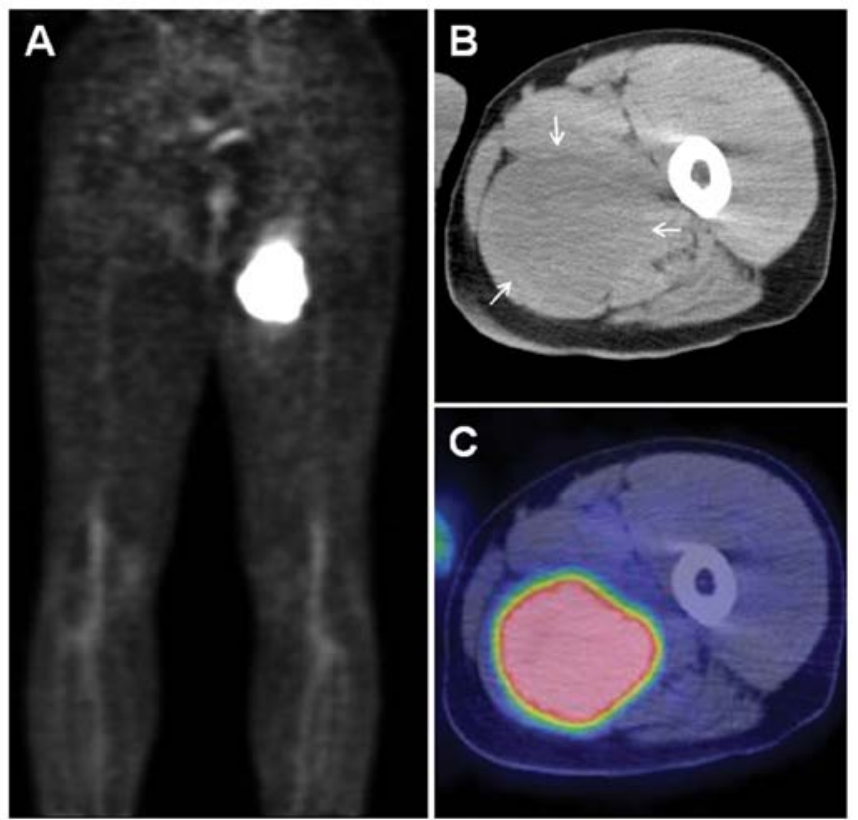

Figure 2. Fluorine-18-deoxyglucose (FDG) positron emission tomography (PET)/computed tomography (CT) images of pleomorphic leiomyosarcoma. (A) PET image demonstrates a markedly increased uptake of FDG in the proximal left thigh. (B) Transaxial CT shows a slightly hypodense intramuscular mass (arrows). (C) Integrated PET/CT image shows a high FDG uptake in the deep soft tissue mass.

on T2-weighted spectral presaturation with inversion recovery sequences (Fig. 1B). T1-weighted contrast-enhanced fatsuppressed sequences showed heterogeneous enhancement of the mass (Fig. 1C). Positron emission tomography imaging demonstrated a markedly increased uptake of fluorine-18-deoxyglucose in the proximal left thigh (Fig. 2A). The maximum standardized uptake value was 20.9. Computed tomography (CT) images showed a hypodense intramuscular mass, with corresponding tracer uptake (Fig. 2B and C). No evidence of distant metastasis was found on chest and abdominal CT scans.

The patient underwent a core needle biopsy and the pathologic diagnosis was pleomorphic leiomyosarcoma. A wide resection of the tumor was performed. Macroscopically, the

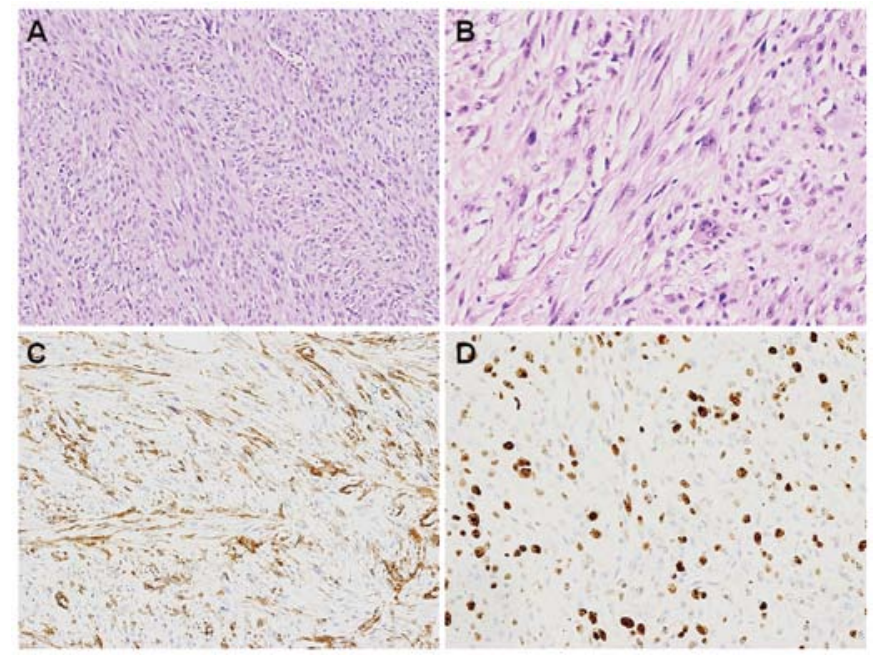

Figure 3. Histologic and immunohistochemical findings of pleomorphic leiomyosarcoma. (A) The tumor is composed of spindle-shaped cells and polygonal cells arranged in interlacing bundles. (B) Multinucleated bizarre cells are found. (C) The tumor cells are immunoreactive for smooth muscle actin. (D) The MIB-1 labeling index is $19.7 \%$.

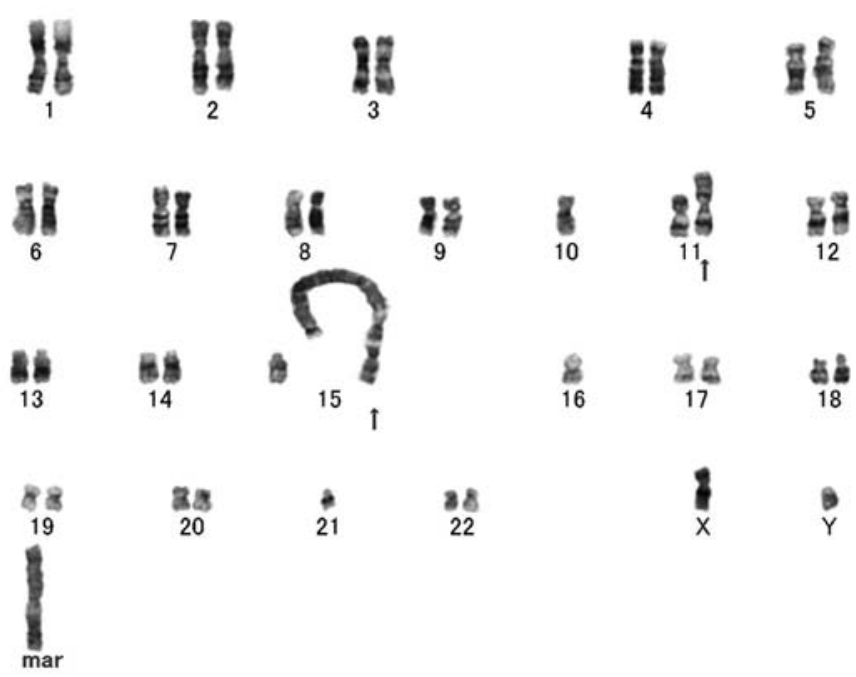

Figure 4. A representative GTG-banded karyotype of pleomorphic leiomyosarcoma, including a giant marker chromosome. Arrows indicate the structural chromosome aberrations. 


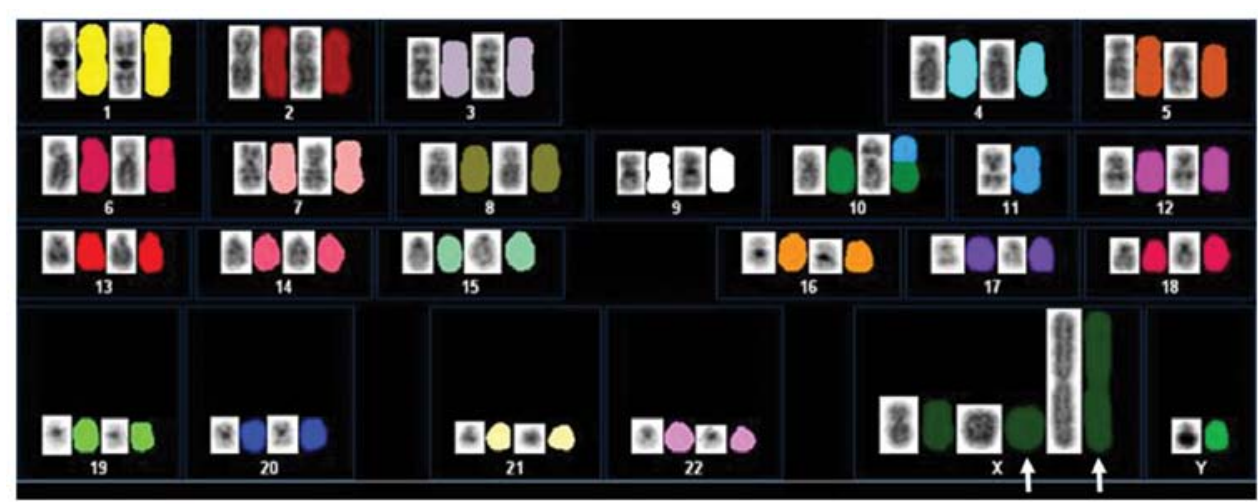

Figure 5. Spectral karyotyping of pleomorphic leiomyosarcoma illustrating the origin of the giant marker and ring chromosomes (arrows). Classified image is displayed alongside the reverse DAPI image.

resected tumor, measuring $10 \times 8 \times 7 \mathrm{~cm}$, had a solid, grayishwhite cut surface. Microscopically, the tumor was composed of a mixture of atypical spindle cells, polygonal cells, and bizarre giant cells forming interlacing bundles and storiform pattern (Fig. 3A and B). Mitotic figures including abnormal forms were frequently seen. Immunohistochemically, the tumor cells were positive for vimentin, smooth muscle actin (Fig. 3C), and desmin, but negative for muscle-specific actin, h-caldesmon, MyoD1, or myogenin. The MIB-1 labeling index was $19.7 \%$ in the highest spot (Fig. 3D). These findings confirmed the diagnosis of pleomorphic leiomyosarcoma. The patient received postoperative adjuvant radiotherapy with a total dose of $60 \mathrm{~Gy}$ and chemotherapy with five cycles of doxorubicin. At 19 months of follow-up, the patient is well without any evidence of local recurrence or distant metastasis.

Cytogenetic analysis. A representative fresh tissue sample was obtained from the surgical resection. Culturing, harvesting, and preparation of slides were performed as described previously (14). Karyotypic descriptions were expressed according to the International System for Human Cytogenetic Nomenclature 2009 (15).

Molecular cytogenetic analysis. Spectral karyotyping (SKY) analysis was performed on unstained cytogenetic preparations according to the manufacturer's instructions (Applied Spectral Imaging, Carlsbad, CA, USA) and as described previously (16). Spectral images were acquired with an SD200 spectral bioimaging system (ASI) and analyzed using SkyView software (ASI). Five metaphase cells were analyzed by SKY.

High molecular weight DNA was extracted from the fresh frozen tissue. CGH was performed as described previously (17). Tumor DNA and reference DNA were labelled by nick translation and hybridized karyotypically normal male slides. The location of aberrant CGH signals was analyzed using an image analysis system (Isis, Carl Zeiss Vision, Oberkochen, Germany) based on an integrated high-sensitivity monochrome charge-coupled device camera and automated $\mathrm{CGH}$ analysis software (MetaSystems $\mathrm{GmbH}$, Altlussheim, Germany). Based on the control experiments, 1.2 and 0.8 were used as cutoff levels for gains and losses, respectively. Gains exceeding the 1.5 threshold were termed high-level amplifications. The heterochromatic regions in chromosomes
1,9 , and 16, the p-arms of the acrocentric chromosomes, and $\mathrm{Y}$ chromosome were excluded from the analysis because of suppression of hybridization with Cot-1 DNA in these regions. Three-color images, green (fluorescein-12-dUTP) for the tumor DNA, red (Spectrum Red) for the reference DNA, and blue (DAPI) for the DNA counterstain, were acquired from at least 10 metaphases.

\section{Results}

Cytogenetic analysis exhibited a complex karyotype with several numerical and structural alterations, including giant marker and ring chromosomes (Fig. 4). The composite karyotype was as follows: 44 48,XY,der(7;21)t(7;?)(p11.2;?)t(21;?) (p11.2;?),-8,-10,add(11)(p13), der(15;21)t(15;?)(p11.2;?)t(21;?) (p11.2;?),-16,-21,dic(21;?)(p11.2;?),-22,+1 2r,+1 2mar [cp20]. SKY analysis revealed that giant marker and ring chromosomes were composed of material from X chromosome (Fig. 5).

Metaphase-based CGH analysis showed high-level amplifications of 1q21-q25 and 12q13-q21 and gains of 1p31-p32, 10p11-p13, 17p11, and 19p13 (Fig. 6). Significant loss of DNA sequences was not detected.

\section{Discussion}

Pleomorphic leiomyosarcoma is a recently described morphological variant of leiomyosarcoma with an aggressive clinical course (18). On the other hand, the term 'dedifferentiated leiomyosarcoma' has also been used to describe leiomyosarcoma with a poorly differentiated pleomorphic component $(2,9,19)$. The pleomorphic component of dedifferentiated leiomyosarcoma is immunohistochemically negative for all muscle markers. Based on staining for muscle markers in the pleomorphic component, we diagnosed the present case as pleomorphic leiomyosarcoma.

Giant marker and/or ring chromosomes have been found in a variety of human neoplasms, but they are particularly common in a subgroup of low-grade or borderline malignant mesenchymal tumors, such as well-differentiated liposarcoma/ atypical lipomatous tumor (20). The origin of these chromosomes cannot be disclosed by chromosome banding techniques due to the suboptimal banding quality and morphological variability. In the present study, we used SKY technique to 


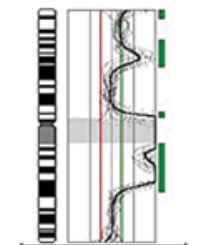

1 (12)

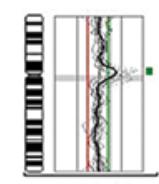

6 (12)

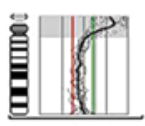

13 (12)
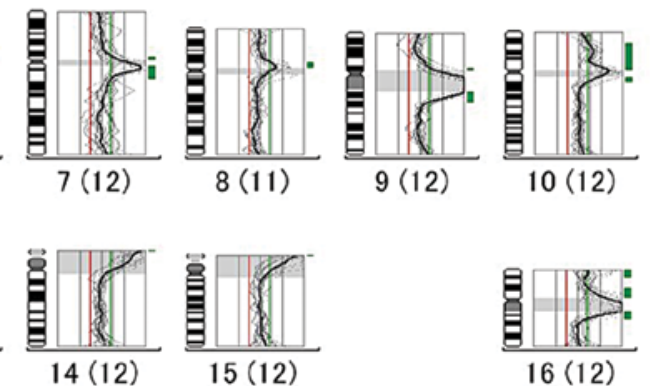

10 (12)
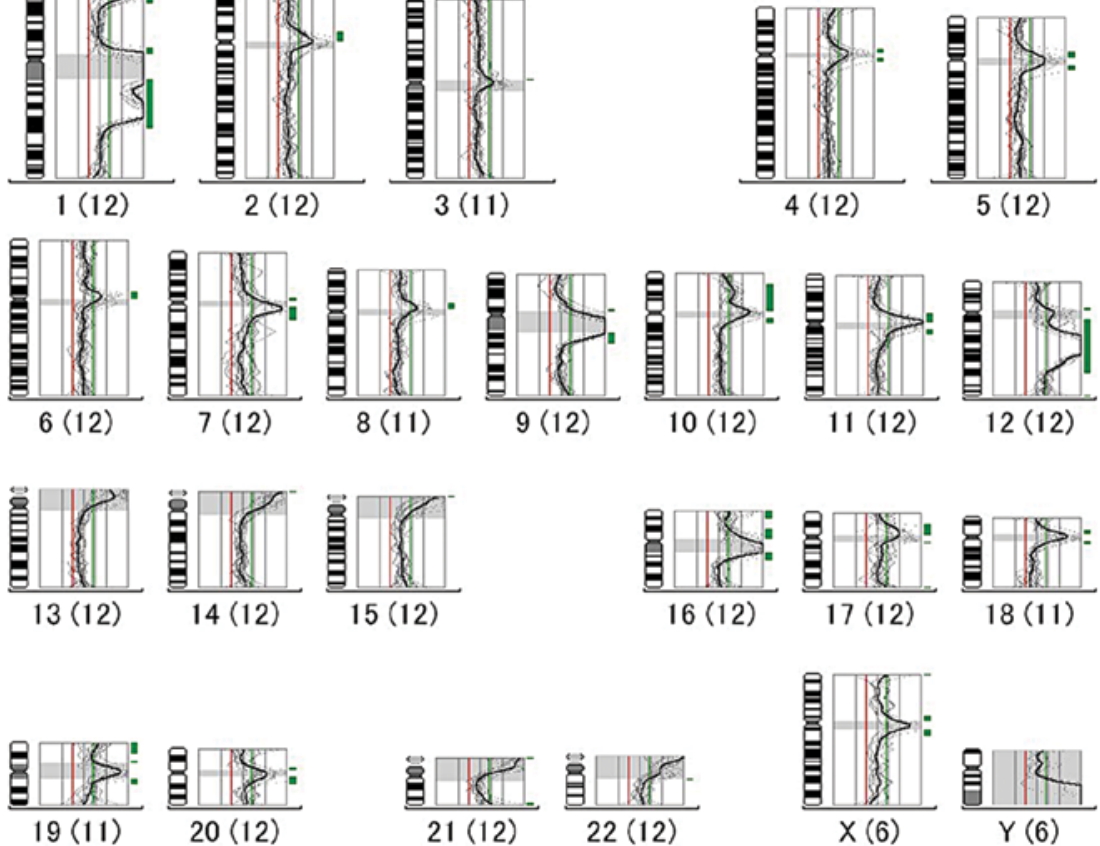

Figure 6. Comparative genomic hybridization profile of pleomorphic leiomyosarcoma showing high-level amplifications of 1q21-q25 and 12q13-q21 and gains of 1p31-p32, 10p11-p13, 17p11, and 19p13. The line in the middle (gray) is the baseline ratio (1.0); the left (red) and right (green) lines indicate ratio values of 0.8 and 1.2, respectively. Bars on the left (red) and right (green) of each frame indicate losses and gains, respectively. The terminology 1 (12) represents 12 aberrations detected on chromosome 1 . The same applies to other chromosomes shown in the profile.

identify the origin of giant marker and ring chromosomes in a pleomorphic soft tissue leiomyosarcoma. SKY analysis showed that giant marker and ring chromosomes were derived from X chromosome. Interestingly, high-level amplification of $\mathrm{Xp}$ has been described in soft tissue and non-soft tissue leiomyosarcomas $(6,21-23)$. The amplified material is frequently carried in mitotically unstable dicentric, multicentric, or ringshaped chromosomes $(24,25)$. Based on these findings, we speculated that ring and/or giant marker chromosomes may contain amplified material from $\mathrm{X}$ chromosome. However, no amplification or gain of $\mathrm{X}$ chromosome was detected by CGH. In general, telomeres play a key role in the maintenance of chromosomal stability. Many human neoplasms exhibit significantly shortened telomeric repeat sequences, which may trigger the formation of telomeric fusions between chromosome arms (26). We suggest that such fusions may lead to ring chromosomes in the present case.

High-level amplifications of 1q21-q25 and 12q13-q21 were found in the present case. Coamplification of these chromosome regions has been observed in several malignant mesenchymal tumors including leiomyosarcoma $(14,27,28)$. Amplification of COAS and PRUNE genes, located at 1q21, has been identified in a subset of leiomyosarcomas $(28,29)$. El-Rifai et al (6) reported that 1q gain was seen in large and very large tumors, but not in any of the small tumors. On the other hand, Ragazzini et al (30) demonstrated that $M D M 2$, $C D K 4$, and TSPAN31 (formerly known as $S A S$ ) genes, located at 12q13-q15, are amplified or overrepresented in at least a subset of pleomorphic soft tissue leiomyosarcomas. These gene alterations seem to play an important role in pleomorphic leiomyosarcoma development, but no clear relationship with clinical outcome has yet been found.
In addition to the amplifications of $1 \mathrm{q}$ and $12 \mathrm{q}$, gains/ amplifications of $17 p$ and $19 p$ have been observed in soft tissue and non-soft tissue leiomyosarcomas, as in our case $(6,11,12,21-23,31)$. Pérot et al (32) demonstrated that MYOCD gene, located at $17 \mathrm{p} 11.2$, is highly amplified and overexpressed in retroperitoneal leiomyosarcomas. $M Y O C D$ encodes a smooth muscle-specific transcriptional co-activator of the serum response factor (33-35). Moreover, they showed that MYOCD expression in sarcoma cell lines not only induces smooth muscle differentiation but also promotes cell migration. These data suggest that MYOCD might constitute a promising therapeutic target. On the other hand, there are several candidate targets on $19 \mathrm{p}$, including $L P S A, M A P 2 K 2$, CDKN2D, and NOTCH3 (36-38). Choong et al (39) found that 19 p13 rearrangements were associated with an increased risk of local recurrence and/or metastasis in MFH. However, the biological significance of $19 \mathrm{p}$ aberrations is still unclear in pleomorphic leiomyosarcomas.

Losses of $10 \mathrm{q}$ and $13 \mathrm{q}$ have also been reported to be recurrent alterations in pleomorphic soft tissue leiomyosarcomas $(10,11,40)$. The tumor suppressor genes PTEN and $R B 1$ are located at $10 \mathrm{q} 23$ and $13 \mathrm{q} 14$, respectively. Functional inactivation of these genes may play a critical role in the development of leiomyosarcoma $(41,42)$. Of note, Hu et al $(11)$ reported that loss of 10q was associated with an aggressive behavior of soft tissue leiomyosarcoma. Loss of 13q14-q21 was also found to be associated with a shortened survival (10).

In summary, our study demonstrates the constitution of giant marker and ring chromosomes in a pleomorphic leiomyosarcoma of soft tissue, and suggests that $\mathrm{X}$ chromosome rearrangements may play a role in the development of this tumor. 


\section{Acknowledgements}

This study was supported in part by the Fukuoka Cancer Society and Medical Care Education Research Foundation.

\section{References}

1. Oda Y, Miyajima K, Kawaguchi K, Tamiya S, Oshiro Y, Hachitanda Y, Oya M, Iwamoto $Y$ and Tsuneyoshi M: Pleomorphic leiomyosarcoma: clinicopathologic and immunohistochemical study with special emphasis on its distinction from ordinary leiomyosarcoma and malignant fibrous histiocytoma. Am J Surg Pathol 25: 1030-1038, 2001

2. Nicolas MM, Tamboli P, Gomez JA and Czerniak BA: Pleomorphic and dedifferentiated leiomyosarcoma: clinicopathologic and immunohistochemical study of 41 cases. Hum Pathol 41: 663-671, 2010.

3. Mertens F, Fletcher CD, Dal Cin P, De Wever I, Mandahl N, Mitelman F, Rosai J, Rydholm A, Sciot R, Tallini G, et al: Cytogenetic analysis of 46 pleomorphic soft tissue sarcomas and correlation with morphologic and clinical features: a report of the CHAMP Study Group. Genes Chromosomes Cancer 22: 16-25, 1998.

4. Mandahl N, Fletcher CD, Dal Cin P, De Wever I, Mertens F, Mitelman F, Rosai J, Rydholm A, Sciot R, Tallini G, et al: Comparative cytogenetic study of spindle cell and pleomorphic leiomyosarcomas of soft tissues: a report from the CHAMP Study Group. Cancer Genet Cytogenet 116: 66-73, 2000.

5. Sandberg AA: Updates on the cytogenetics and molecular genetics of bone and soft tissue tumors: leiomyosarcoma. Cancer Genet Cytogenet 161: 1-19, 2005.

6. El-Rifai W, Sarlomo-Rikala M, Knuutila S and Miettinen M DNA copy number changes in development and progression in leiomyosarcomas of soft tissues. Am J Pathol 153: 985-990, 1998.

7. Wang R,Lu YJ, Fisher C, Bridge JA and Shipley J: Characterization of chromosome aberrations associated with soft-tissue leiomyosarcomas by twenty-four-color karyotyping and comparative genomic hybridization analysis. Genes Chromosomes Cancer 31: $54-64,2001$

8. Derré J, Lagacé R, Nicolas A, Mairal A, Chibon F, Coindre JM, Terrier P, Sastre X and Aurias A: Leiomyosarcomas and most malignant fibrous histiocytomas share very similar comparative genomic hybridization imbalances: an analysis of a series of 27 leiomyosarcomas. Lab Invest 81: 211-215, 2001.

9. Evans HL and Shipley J: Leiomyosarcoma. In: World Health Organization Classification of Tumours: Pathology and Genetics of Tumours of Soft Tissue and Bone. Fletcher CDM, Unni KK and Mertens F (eds). IARC Press, Lyon, pp131-134, 2002.

10. Wang R, Titley JC, Lu YJ, Summersgill BM, Bridge JA, Fisher C and Shipley J: Loss of 13q14-q21 and gain of 5 p14-pter in the progression of leiomyosarcoma. Mod Pathol 16: 778-785, 2003.

11. Hu J, Rao UN, Jasani S, Khanna V, Yaw K and Surti U: Loss of DNA copy number of $10 \mathrm{q}$ is associated with aggressive behavior of leiomyosarcomas: a comparative genomic hybridization study: Cancer Genet Cytogenet 161: 20-27, 2005.

12. Larramendy ML, Kaur S, Svarvar C, Böhling T and Knuutila S: Gene copy number profiling of soft-tissue leiomyosarcomas by array-comparative genomic hybridization. Cancer Genet Cytogenet 169: 94-101, 2006.

13. Yang J, Du X, Chen K, Ylipää A, Lazar AJ, Trent J, Lev D, Pollock R, Hao X, Hunt K and Zhang W: Genetic aberrations in soft tissue leiomyosarcoma. Cancer Lett 275: 1-8, 2009.

14. Nishio J, Aoki M, Nabeshima K, Iwasaki $\mathrm{H}$ and Naito $\mathrm{M}$ : Cytogenetic and molecular cytogenetic findings in giant dedifferentiated liposarcoma of the thigh. Oncol Rep 27: 764-768, 2012

15. Shaffer LG, Slovak ML and Campbell LJ (eds): ISCN (2009): An International System for Human Cytogenetic Nomenclature. Karger, Basel, 2009.

16. Nishio J, Iwasaki H, Althof PA, Naumann S, Ishiguro M, Haraoka S, Iwashita A, Iwasaki A, Kaku Y, Kaneko Y, et al: Identification of a ring chromosome with spectral karyotyping in a pleural synovial sarcoma. Cancer Genet Cytogenet 160: 174-178, 2005.
17. Nishio J, Iwasaki H, Ohjimi Y, Ishiguro M, Koga T, Isayama T, Naito $\mathrm{M}$ and Kikuchi M: Gain of Xq detected by comparative genomic hybridization in elastofibroma. Int J Mol Med 10: 277-280, 2002.

18. Fletcher CDM: Pleomorphic malignant fibrous histiocytoma: fact or fiction? A critical reappraisal based on 159 tumors diagnosed as pleomorphic sarcoma. Am J Surg Pathol 16: 213-218, 1992.

19. Chen E, O'Connell F and Fletcher CDM: Dedifferentiated leiomyosarcoma: clinicopathological analysis of 18 cases. Histopathology 59: 1135-1143, 2011.

20. Nishio J: Contributions of cytogenetics and molecular cytogenetics to the diagnosis of adipocytic tumors. J Biomed Biotechnol 2011: 524067, 2011.

21. Otaño-Joos M, Mechtersheimer G, Ohl S, Wilgenbus KK, Scheurlen W, Lehnert T, Willeke F, Otto HF, Lichter P and Joos S: Detection of chromosomal imbalances in leiomyosarcoma by comparative genomic hybridization and interphase cytogenetics. Cytogenet Cell Genet 90: 86-92, 2000.

22. Levy B, Mukherjee T and Hirschhorn K: Molecular cytogenetic analysis of uterine leiomyoma and leiomyosarcoma by comparative genomic hybridization. Cancer Genet Cytogenet 121: $1-8,2000$.

23. Hu J, Khanna V, Jones M and Surti U: Genomic alterations in uterine leiomyosarcomas: potential markers for clinical diagnosis and prognosis. Genes Chromosomes Cancer 31: 117-124, 2001.

24. Gisselsson D, Björk J, Höglund M, Mertens F, Dal Cin P, Akerman $\mathrm{M}$ and Mandahl N: Abnormal nuclear shape in solid tumors reflects mitotic instability. Am J Pathol 158: 199-206, 2001.

25. Iwasaki H, Nabeshima K, Nishio J, Jimi S, Aoki M, Koga K, Hamasaki M, Hayashi $\mathrm{H}$ and Mogi A: Pathology of soft-tissue tumors: daily diagnosis, molecular cytogenetics and experimental approach. Pathol Int 59: 501-521, 2009.

26. Gisselsson D, Jonson T, Petersén A, Strömbeck B, Dal Cin P, Höglund M, Mitelman F, Mertens F and Mandahl N: Telomere dysfunction triggers extensive DNA fragmentation and evolution of complex chromosome abnormalities in human malignant tumors. Proc Natl Acad Sci USA 98: 12683-12688, 2001.

27. Forus A, Weghuis DO, Smeets D, Fodstad O, Myklebost O and van Kessel AG: Comparative genomic hybridization analysis of human sarcomas: I. Occurrence of genomic imbalances and identification of a novel major amplicon at 1q21-q22 in soft tissue sarcomas. Genes Chromosomes Cancer 14: 8-14, 1995.

28. Nilsson M, Meza-Zepeda LA, Mertens F, Forus A, Myklebost O and Mandahl N: Amplification of chromosome 1 sequences in lipomatous tumors and other sarcomas. Int J Cancer 109: 363-369, 2004

29. Forus A, D'Angelo A, Henriksen J, Merla G, Maelandsmo GM, Flørenes VA, Olivieri S, Bjerkehagen B, Meza-Zepeda LA, del Vecchio Blanco F, et al: Amplification and overexpression of PRUNE in human sarcomas and breast carcinomas - a possible mechanism for altering the $\mathrm{nm} 23-\mathrm{H} 1$ activity. Oncogene 20: 6881-6890, 2001.

30. Ragazzini P, Gamberi G, Pazzaglia L, Serra M, Magagnoli G, Ponticelli F, Ferrari C, Ghinelli C, Alberghini M, Bertoni F, et al: Amplification of CDK4, MDM2, SAS and GLI genes in leiomyosarcoma, alveolar and embryonal rhabdomyosarcoma. Histol Histopathol 19: 401-411, 2004.

31. Meza-Zepeda LA, Kresse SH, Barragan-Polania AH, Bjerkehagen B, Ohnstad HO, Namløs HM, Wang J, Kristiansen BE and Myklebost O: Array comparative genomic hybridization reveals distinct DNA copy number differences between gastrointestinal stromal tumors and leiomyosarcomas. Cancer Res 66: 8984-8993, 2006.

32. Pérot G, Derré J, Coindre JM, Tirode F, Lucchesi C, Mariani O, Gibault L, Guillou L, Terrier P and Aurias A: Strong smooth muscle differentiation is dependent on myocardin gene amplification in most human retroperitoneal leiomyosarcomas. Cancer Res 69: 2269-2278, 2009.

33. Du KL, Ip HS, Li J, Chen M, Dandre F, Yu W, Lu MM, Owens GK and Parmacek MS: Myocardin is a critical serum response factor cofactor in the transcriptional program regulating smooth muscle cell differentiation. Mol Cell Biol 23: 2425-2437, 2003.

34. Wang Z, Wang DZ, Pipes GC and Olson EN: Myocardin is a master regulator of smooth muscle gene expression. Proc Natl Acad Sci USA 100: 7129-7134, 2003.

35. Pipes GC, Creemers EE and Olson EN: The myocardin family of transcriptional coactivators: versatile regulators of cell growth, migration, and myogenesis. Genes Dev 20: 1545-1556, 2006. 
36. Gill S, Stratton MR, Patterson H, Spurr NK, Fisher C, Gusterson BA and Cooper CS: Detection of transforming genes by transfection of DNA from primary soft-tissue tumours. Oncogene 6: 1651-1656, 1991.

37. Pryor JG, Brown-Kipphut BA, Iqbal A and Scott GA: Microarray comparative genomic hybridization detection of copy number changes in desmoplastic melanoma and malignant peripheral nerve sheath tumor. Am J Dermatopathol 33: 780-785, 2011.

38. Bellavia D, Checquolo S, Campese AF, Felli MP, Gulino A and Screpanti I: Notch3: from subtle structural differences to functional diversity. Oncogene 27: 5092-5098, 2008.

39. Choong PF, Mandahl N, Mertens F, Willén H, Alvegård T, Kreicbergs A, Mitelman F and Rydholm A: 19p+ marker chromosome correlates with relapse in malignant fibrous histiocytoma. Genes Chromosomes Cancer 16: 88-93, 1996.
40. Larramendy ML, Gentile M, Soloneski S, Knuutila S and Böhling T: Does comparative genomic hybridization reveal distinct differences in DNA copy number sequence patterns between leiomyosarcoma and malignant fibrous histiocytoma? Cancer Genet Cytogenet 187: 1-11, 2008.

41. Dei Tos AP, Maestro R, Doglioni C, Piccinin S, Libera DD, Boiocchi $\mathrm{M}$ and Fletcher CDM: Tumor suppressor genes and related molecules in leiomyosarcoma. Am J Pathol 148: 1037-1045, 1996.

42. Hernando E, Charytonowicz E, Dudas ME, Menendez S, Matushansky I, Mills J, Socci ND, Behrendt N, Ma L, Maki RG, et al: The AKT-mTOR pathway plays a critical role in the development of leiomyosarcomas. Nat Med 13: 748-753, 2007. 